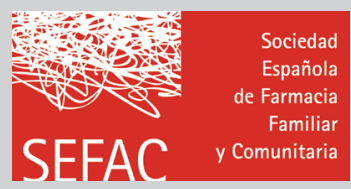

\title{
¿Por qué de nuevo el sarampión como problema de salud?
}

\author{
Maricarmen Magro Horcajada \\ Coordinadora del grupo de Enfermedades infecciosas e inmunología de SEFAC.
}

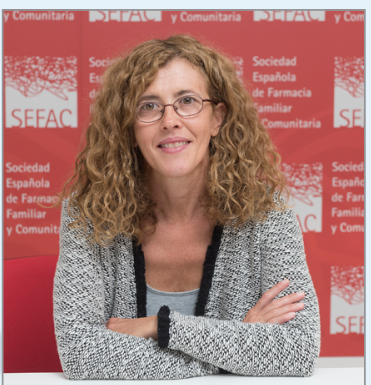

Maricarmen Magro

\section{PALABRAS CLAVE}

Vacunación, vacunas, sarampión, farmacéutico comunitario, salud pública

\section{KEYWORDS}

Vaccination, vaccines, measles, community drug, public health
¿Qué está ocurriendo con el sarampión? Es una pregunta que todos los profesionales sanitarios nos estamos haciendo, a raíz de distintas noticias recogidas en prensa y redes sociales desde 2018, que han generado confusión, dudas e intranquilidad en la población. Parecía que era una enfermedad casi erradicada y de la que apenas ya se hablaba dejando paso a enfermedades de mayor interés y actualidad como la meningitis, la neumonía, la gripe, el virus del papiloma humano, el virus del herpes zóster, etc. Sin embargo, desde 2018 el sarampión está muy presente siendo noticia casi a diario en distintos medios de comunicación, creando inquietud al Comité Asesor de Vacunas, a la Asociación Española de Pediatría, a los expertos en salud pública, a las sociedades científicas médicas, enfermería y, como no, a SEFAC. Todas estas entidades buscan una solución a este problema sanitario. ¿A qué se debe esta preocupación? La causa no es otra que los últimos brotes detectados en la región europea de la Organización Mundial de la Salud (OMS) en 2018 en Europa y el mal comienzo de 2019 en Estados Unidos. Brotes motivados por el incremento de la desconfianza en la seguridad y eficacia de las vacunas por parte de los movimientos antivacunas y por las restricciones en diferentes países de las políticas vacunales como consecuencia de conflictos bélicos y de la pobreza, lo que han hecho que la población no sea vacunada por falta de recursos. En España no es tan preocupante, aunque no se debe bajar la guardia teniéndose en cuenta las señales de alarma de unas coberturas vacunales que se están restringiendo.

En 2019, según datos del European Centre for Disease Prevention and Control (ECDC) (informe primer semestre 2019), en Europa se registraron más de 90.000 casos de sarampión y 233 en Es- paña frente a los 35 notificados en 2016, cuando se creía a nuestro país "libre "de sarampión. En Reino Unido, caracterizado por su buena política vacunal, la enfermedad se consideraba eliminada en 2016; sin embargo, en la actualidad se ha restablecido la transmisión endémica en dicho país, junto con Albania, Grecia, y República Checa. Solo Austria y Suiza, recuperan la calificación de libre de sarampión.

El sarampión es una enfermedad muy contagiosa causada por un virus que se transmite por vía aérea al sistema respiratorio. Se caracteriza por unas típicas manchas en la piel de color rojo y blancas en el interior de la boca. No es una enfermedad banal o leve, ya que puede derivar en complicaciones severas respiratorias, neurológicas, aumentar la vulnerabilidad de otras enfermedades e incluso la muerte. Antes de que existiera la vacuna para prevenirla se combatía de forma natural generando una inmunidad natural de por vida. Si la enfermedad aparece en la edad adulta, cuando el sistema inmunitario empieza a estar más debilitado (inmunosenescencia), esas complicaciones podrán aparecer con mayor probabilidad.

El farmacéutico comunitario tiene una labor crucial de informar, reforzar los mensajes emitidos por el resto de profesionales de la salud y asesorar a todos aquellos pacientes que acuden a nuestra farmacia con la siguiente pregunta: ¿Tengo que vacunarme del sarampión?

\section{¿Cómo actuamos nosotros?}

Siempre basándonos en las recomendaciones de vacunación del Ministerio de Sanidad, Consumo y Bienestar Social en la población infantil, adolescente y adulta a partir de las últimas revisiones realizadas en las diferentes comunidades 
autónomas y de las efectuadas en el seno del Consejo Interterritorial del Sistema Nacional de Salud (CISNS) aprobadas en 2018: https://www.mscbs.gob.es/profesionales/ saludPublica/prevPromocion/vacunaciones/docs/Vacunacion_poblacion_adulta.pdf. Las actualizaciones incluidas están basadas en la evidencia científica y en la evaluación del riesgo de cada grupo poblacional en función de la edad, los antecedentes de vacunación, pertenencia a algún grupo de riesgo y la actividad profesional desarrollada. Por tanto, no debemos dar una opinión personal respecto a la vacunación del sarampión. Desde mi punto de vista como farmacéutica comunitaria y conocedora de la problemática en temas relacionados con la vacunación, nuestros mensajes emitidos deber ser los mismos que la información recibida por parte de otros profesionales sanitarios. De esta forma, ayudamos al paciente a no tener dudas y evitar dirigirse a fuentes de información "de incierta procedencia" que le llevaría a tomar decisiones erróneas frente a la prevención de enfermedades infecciosas mediante la vacunación.

Debemos transmitir seguridad en nuestras respuestas. Para ello, necesitamos adelantarnos a la información emitida por los medios de comunicación con el fin de que no nos pillen en un "renuncio". ¿A quién no le ha ocurrido estar "fuera de juego" respecto a que pasa con el sarampión? ¿A quién no le ha surgido en la farmacia el dilema entre recomendar o no vacunarse frente al sarampión? Seguramente, dudaremos a la hora de responder a esta última pregunta ya que somos sabedores de que el sarampión en nuestro país no es endémico y que gracias a las elevadas coberturas vacunales en la edad infantil, se podría pensar que "a mí no me va a pasar". En las personas nacidas antes de 1970 se asume que son inmunes por haber padecido la enfermedad con anterioridad, pero asumir no es asegurar al cien por cien que todos la han padecido.

\section{¿Quién debería vacunarse frente al sarampión?}

Vacuna del sarampión triple vírica (TV) para todos los nacidos a partir de 1970 que NO estén vacunados y NO hayan pasado la enfermedad, exceptuando las embarazadas. Ante la duda es mejor vacunar, siendo dos dosis separadas cuatro semanas, independientemente de la edad. Aquí no nos olvidemos de tres grupos de población, los profesionales sanitarios (sí, nosotros), que tienen un mayor riesgo de adquisición de sarampión que la población general; las mujeres en edad fértil, y las personas que realicen viajes internacionales. Hay que destacar que los más afectados son los que tienen entre 40-50 años; es decir los que nacieron entre 1970-1980, cuya vacunación se llevaría a cabo en su centro de salud de forma gratuita, previa prescripción por parte de su médico. Los pacientes mayores de 50 años estuvieron en contacto con el virus de niños (por tanto, tienen una probabilidad alta de haber padecido la enfermedad y estar inmunizados). Desde la farmacia comunitaria, y como profesional sanitario que somos, deberíamos preguntar al menos a cualquier paciente, familiar o cuidador nacido antes del 1981 (año en el que se generalizó la vacunación TV) si recuerdan haberla padecido o si está vacunado y, en caso negativo, informar de los beneficios de la vacunación TV y derivar a atención primaria para que el médico valore la situación y actúe según su criterio.

Para finalizar, la OMS ha verificado que nuestro país continúa en estado de eliminación que no es sinónimo de erradicación. El Ministerio de Sanidad, Consumo y Bienestar Social ha señalado que no hay motivos que justifiquen un cambio de la estrategia ni de las recomendaciones de vacunación frente a sarampión ya establecida y quedan descritas anteriormente en esta editorial.

"Si no se logra y mantiene una alta cobertura de inmunización en todas las comunidades, tanto los niños como los adultos sufrirán innecesariamente y algunos morirán trágicamente", ha comentado el presidente de la Comisión Regional Europea de Verificación para la Eliminación del Sarampión y la Rubeola RVC, Günter Pfaff.

Las vacunas salvan vidas y no son un gasto, son una inversión en salud.

Desde las farmacias comunitarias debemos apoyar cualquier iniciativa y campaña sanitaria que velen por la salud de nuestra población. En este caso frente al sarampión. 